\title{
Origin of Supercharging in Electrospray Ionization of Noncovalent Complexes from Aqueous Solution
}

\author{
Harry J. Sterling and Evan R. Williams \\ Department of Chemistry, University of California-Berkeley, Berkeley, California, USA
}

\begin{abstract}
The use of $m$-nitrobenzyl alcohol ( $m$-NBA) to enhance charging of noncovalent complexes formed by electrospray ionization from aqueous solutions was investigated. Addition of up to $1 \% \mathrm{~m}$-NBA can result in a significant increase in the average charging of complexes, ranging from $\sim 13 \%$ for the homo-heptamer of NtrC4-RC (317 kDa; maximum charge state increases from $42+$ to $44+$ ) to $\sim 49 \%$ for myoglobin ( $17.6 \mathrm{kDa}$; maximum charge state increases from $9+$ to $16+)$. Charge state distributions of larger complexes obtained from heated solutions to which no $m$-NBA was added are remarkably similar to those containing small amounts of $m$-NBA. Dissociation of the complexes through identical channels both upon addition of higher concentrations of $m$-NBA and heating is observed. These results indicate that the enhanced charging upon addition of $m$-NBA to aqueous electrospray solutions is a result of droplet heating owing to the high boiling point of $m$-NBA, which results in a change in the higher-order structure and/or dissociation of the complexes. For monomeric proteins and small complexes, the enhancement of charging is lower for heated aqueous solutions than from solutions with $m$-NBA because rapid folding of proteins from heated solutions that do not contain $m$-NBA can occur after the electrospray droplet is formed and is evaporatively cooled. (J Am Soc Mass Spectrom 2009, 20, 1933-1943) @ 2009 Published by Elsevier Inc. on behalf of American Society for Mass Spectrometry
\end{abstract}

A $\mathrm{n}$ important advantage of electrospray ionization (ESI) for the analysis of large molecules, including synthetic [1, 2] and biopolymers [3, 4], large complexes [5-8], and even intact viruses [9, 10], is the formation of ions with multiple charges. Multiple charging decreases the $\mathrm{m} / \mathrm{z}$ of large molecular ions to a range where virtually any type of mass spectrometer can perform measurements. The performance of many instruments, including orbitrap [11] or Fourier-transform ion cyclotron resonance mass spectrometers [12], improves with decreasing $m / z$, making it possible to obtain molecular masses of peptides, proteins, or other macromolecules with low ppm and even sub-ppm mass measuring accuracy, even when present in complex mixtures [13]. Multiple charging also greatly enhances structural information obtainable from tandem and even $\mathrm{MS}^{n}$ experiments [8, 14], making it possible to obtain significant sequence information from proteins as large as $229 \mathrm{kDa}$ [14].

The detailed mechanism of ion formation and the origin of ion charging in ESI has been hotly debated [15-21]. Numerous factors can influence the extent of charging observed, including ion conformation [22, 23], solvent and analyte gas-phase basicity [24-26], droplet

Address reprint requests to Professor E. R. Williams, College of Chemistry, University of California-Berkeley, B42 Hildebrand Hall, Berkeley, CA 94720, USA. E-mail: williams@cchem.berkeley.edu size [27], instrumental conditions [28], etc. Small basic molecules, either added to the solution [24] or in the gas phase [24-26], can result in a significant lowering of the charge state distribution of a protein owing to competition for charge. Analyte charge reduction has also been achieved by electrospray ionization in the presence of $\alpha$ particles from a ${ }^{210}$ Po source [29], reaction with ions of the opposite polarity [30], or by in-source collisions, which can increase rates of endothermic proton transfer and dissociation of more highly charged ions [25, 26].

Although many methods can reduce charging of analyte molecules in ESI, comparatively few methods enhance multiple charging. Charge state distributions of proteins formed by ESI from solutions in which proteins are denatured are shifted to significantly lower $m / z$ (higher charge states) than when formed from buffered aqueous solutions, where the structures are native or native-like [22, 23]. Information about different conformations that exist in solution have been obtained by modeling the often overlapping envelopes of charge state distributions [31]. In addition to protein denaturation, addition of low concentrations of some small molecules, such as glycerol or m-nitrobenzyl alcohol ( $m$-NBA), can result in a dramatic increase in both the average and maximum charge states of ions $[19,32-38]$. For example, addition of $1.0 \% \mathrm{~m}$-NBA to $47 / 50 / 3 \%$ water/methanol/acetic acid solutions containing cytochrome $c$ results in a shift in the average 
(and maximum) charge states from 17.3 (21) to 20.8 (24) [33]. This "supercharging" phenomenon can be useful in tandem MS experiments for protein and peptide sequencing [19, 34-38], particularly for electron capture dissociation experiments where the capture cross section increases significantly with increasing precursor charge state $[39,40]$. Ion-ion collision rates also increase significantly with increasing charge state [41], and addition of $m$-NBA to increase the charge states of tryptic peptides and phosphopeptides was found to greatly improve protein identification in electron-transfer dissociation experiments [38]. Because of the low volatility of these compounds compared with that of water/ methanol, their concentration increases as solvent evaporation of the more volatile components from the droplets occurs. For solutions that contain significant fractions of methanol, this will result in an increase of the droplet surface tension, and a greater charge density necessary to reach the Rayleigh limit [42], which for a spherical droplet is given by:

$$
z_{R} e=8 \pi\left(\varepsilon_{0} \gamma R^{3}\right)^{1 / 2}
$$

where $z_{\mathrm{R}}$ is the unit charge limit, $e$ is the elementary charge, $\varepsilon_{0}$ is the permittivity of the surrounding medium, $\gamma$ is the surface tension, and $R$ is the droplet radius. In contrast, the charge states of ions formed from pure aqueous solutions to which small amounts of $m$-NBA is added can be reduced owing to the lower surface tension of $m$-NBA $(50 \pm 5 \mathrm{mN} / \mathrm{m})$ [33] compared with that of water $\left(71.99 \mathrm{mN} / \mathrm{m}\right.$ at $\left.25^{\circ} \mathrm{C}\right)$ [43]. For example, the average charge state of a poly(propyleneimine) (DAB-16), which cannot undergo large conformational changes [44], is decreased when $m$-NBA is added to aqueous solutions containing this molecule, but is increased when $m-\mathrm{NBA}$ is added to methanol solutions [19] $\left(22.07 \mathrm{mN} / \mathrm{m}\right.$ at $\left.25^{\circ} \mathrm{C}\right)$ [43].

In a series of experiments by Grandori and coworkers [45-47], the charge state distributions of proteins were not directly correlated to the solvent surface tension. However, the difficulty of distinguishing effects of changes in surface tension versus effects of changing protein conformation and other known factors that affect charging make it difficult to draw definitive conclusions from these experiments.

Recently, Loo and coworkers demonstrated that addition of $m$-NBA to aqueous solutions results in increased charging of noncovalent complexes [48]. Charge enhancements ranging from $8 \%$ for the $690 \mathrm{kDa}$ $\alpha_{7} \beta_{7} \beta_{7} \alpha_{7} 20$ S proteasome complex to $48 \%$ for the zincbound $29 \mathrm{kDa}$ carbonic anhydrase-II protein were observed. Because the surface tension of $m$-NBA is lower than that of water, addition of $m$-NBA to aqueous solutions should, in the absence of other factors, result in a lowering of surface tension and, hence, a lower charge state distribution leading Loo and coworkers to question the role of surface tension on charging, although no other mechanism to explain these results was proposed.
Here, effects of addition of small amounts of $m$-NBA on noncovalent complexes are investigated and compared with results from heating the same solutions without $m$-NBA. These results indicate that the charge enhancement effect of $m$-NBA on noncovalent complexes electrosprayed from aqueous solution is a result of droplet heating owing to the high boiling point of $m$-NBA, which results in preferential evaporation of water from the droplet and reduced evaporative cooling. Conformational changes and even dissociation of the complexes can occur as a result of the droplet heating.

\section{Experimental}

Mass spectra were acquired using a quadrupole timeof-flight mass spectrometer equipped with a Z-spray ion source (Q-TOF Premier, Waters, Milford, MA, USA). Ions were formed using nanoelectrospray emitters prepared by pulling borosilicate capillaries $(1.0 \mathrm{~mm}$ o.d./0.78 mm i.d.; Sutter Instruments, Novato, CA, USA) to a tip i.d. of $\sim 1 \mu \mathrm{m}$ with a Flaming/Brown micropipette puller (model P-87, Sutter). A platinum wire (0.127 $\mathrm{mm}$ diameter, Sigma, St. Louis, MO, USA) was inserted through the capillary into the solution and electrospray was initiated and maintained by applying $1-1.3 \mathrm{kV}$ to the wire relative to instrument ground. The capillaries were resistively heated with $\mathrm{NiCr}$ wire wrapped around a cylindrical aluminum collar that is solid except for a small hole through which the capillary is held (see Supplemental Information, which can be found in the electronic version of this article). The temperature of the heating collar was monitored continuously with a thermocouple and temperature meter (Omega, Stamford, CT, USA). m-NBA was purchased from Sigma-Aldrich (St. Louis, MO, USA) and was used without further purification. Raw data were smoothed three times using the Waters MassLynx software mean smoothing algorithm with a $25 \mathrm{Da}$ window for the $\mathrm{PA}_{\mathrm{x}}\left(\mathrm{LF}_{\mathrm{N}}\right)_{\mathrm{y}}$ and NtrC4-RC complexes and a 3 Da window for myoglobin. Relative abundances of proteins and complexes were estimated by summing the intensities of each charge state of a given protein complex and dividing that value by the sum of the intensities for all the complexes and proteins. The instrument was calibrated with CsI clusters formed by nano-ESI of a $24 \mathrm{mg} / \mathrm{mL}$ solution of CsI in 70:30 Milli-Q:2-propanol (Millipore, Billerica, MA, USA) before mass measurement.

The $\mathrm{PA}_{\mathrm{x}}\left(\mathrm{LF}_{\mathrm{N}}\right)_{\mathrm{y}}$ proteins were provided by Professor Bryan A. Krantz (University of California, Berkeley) and were electrosprayed from a solution containing 5 $\mathrm{mM}$ ammonium bicarbonate and $100 \mathrm{mM}$ ammonium acetate, $\mathrm{pH}=7.8$, at a protein complex concentration of $\sim 5 \mu \mathrm{M}$. The protein complexes therein are truncation constructs of the Anthrax toxin prepore assembly, composed of heptameric [49] and octameric [56] ringshaped oligomers of the protective antigen (PA) protein that bind up to three [49] and four [56] lethal factor (LF) ligand proteins, respectively. The NtrC4-RC protein was provided by Professor David E. Wemmer (Univer- 
sity of California, Berkeley) and was electrosprayed from a solution containing $600 \mathrm{mM}$ ammonium acetate, $\mathrm{pH}=7.8$, at a protein concentration of $\sim 25 \mu \mathrm{M}$. The protein complexes in this solution are homo-oligomers of a truncation construct of a $\sigma^{54}$ activator protein from Aquifex aeolicus [50]. Myoglobin solutions were prepared from lyophilized powder (Sigma-Aldrich) by dissolution in $40 \mathrm{mM}$ ammonium acetate, $\mathrm{pH}=7.8$, at a protein concentration of $\sim 5 \mu \mathrm{M}$.

\section{Results}

To test the hypothesis that the effect of supercharging observed by adding $m$-NBA to aqueous solutions containing noncovalent complexes is due to a change in the higher-order structure of the complex owing to heating of the electrospray droplet from which they are formed, experiments with three different complexes ranging in size from 17.6 to $632 \mathrm{kDa}$ were performed. In these experiments, ESI mass spectra were obtained from solutions using nanospray capillaries surrounded by an aluminum collar, the temperature of which can be accurately varied from room temperature to $>90^{\circ} \mathrm{C}$ by resistive heating (see Supplemental Information). These spectra were compared with those obtained at room temperature under identical conditions but to which small amounts of $m$-NBA were added to otherwise identical solutions. Results for these three complexes are described below.

\section{Myoglobin}

An ESI mass spectrum of myoglobin (17.6 kDa) electrosprayed from aqueous solution containing $40 \mathrm{mM}$ ammonium acetate, $\mathrm{pH}=7.8$, at $26^{\circ} \mathrm{C}$, is shown in Figure $1 \mathrm{a}$. The most abundant charge state distribution corresponds to myoglobin $(\sim 94 \%)$ and a significantly less abundant charge state distribution corresponding to apomyoglobin $(\sim 6 \%)$ is also observed. Both charge state distributions are centered at the $8+$ charge state,

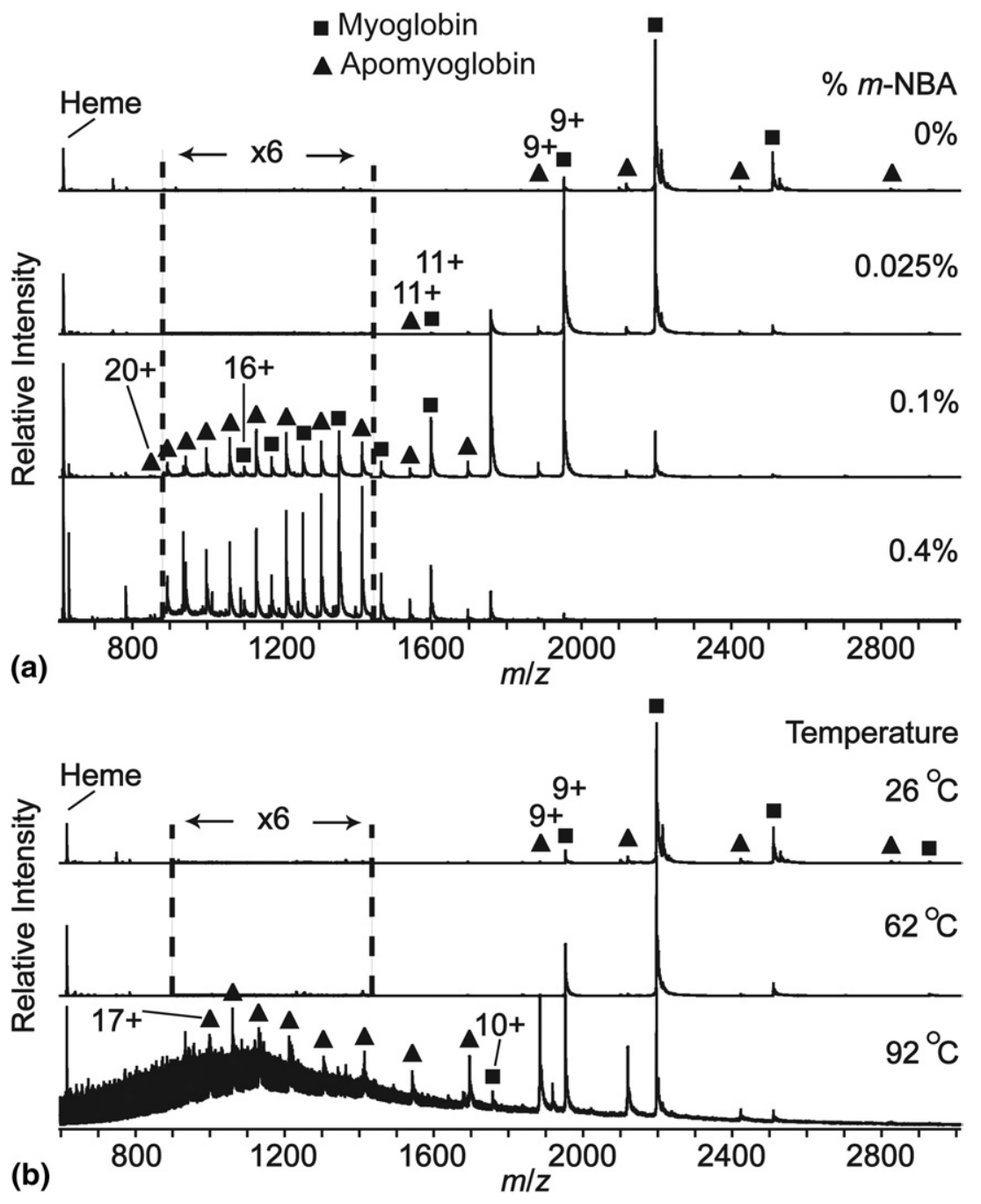

Figure 1. Mass spectra of myoglobin and apomyoglobin as a function of (a) $\% m$-NBA and (b) heating collar temperature. The region between $\mathrm{m} / \mathrm{z} 880$ and 1440 is expanded $\times 6$ in all but the $92^{\circ} \mathrm{C}$ spectrum. 
with an average (and maximum) charge of 7.9 (9) and 7.6 (9) for myoglobin and apomyoglobin, respectively. Addition of even small amounts of $m$-NBA results in a significant change in both the charge state distributions and relative abundances of these two ions (Table 1 , Figure 1a). With $0.4 \% \mathrm{~m}$-NBA, the average (and maximum) charge states are 11.8 (16) and 13.9 (20) for myoglobin and apomyoglobin, respectively. Thus, addition of $m$-NBA to solutions in which the conformation of myoglobin should be "native" results in a significant increase in both the maximum and average charge state. Furthermore, the charge state of myoglobin appears to reach a maximum at which point loss of the heme co-factor occurs. The newly formed apomyoglobin then takes on additional charges. Significantly, the relative abundances of the myoglobin and apomyoglobin ions change dramatically with the addition of $m$-NBA (Figure 2a). Without $m$-NBA, the abundance of apomyoglobin is only $\sim 7 \%$ that of myoglobin but this value is $\sim 76 \%$ with $0.4 \% \mathrm{~m}$-NBA. Thus, addition of even small amounts of $m$-NBA results in significant loss of heme from myoglobin.

Heating of the solution in the capillary (no $m$-NBA) also results in a change in the charge state distributions of these ions, although this effect is less dramatic than when $m$-NBA is added to the solutions. At $92^{\circ} \mathrm{C}$, the highest temperature at which signal could be obtained, the average (and maximum) charge state of myoglobin and apomyoglobin are 8.5 (10) and 11.9 (17), respectively. Again, myoglobin appears to reach a maximum charge state that is lower than that for apomyoglobin. The relative abundances of these ions also change dramatically with solution heating; the relative abundances of myoglobin and apomyoglobin are $\sim 34 \%$ and $\sim 66 \%$, respectively, at $92{ }^{\circ} \mathrm{C}$ compared with $\sim 94 \%$ and $\sim 6 \%$ at $26^{\circ} \mathrm{C}$ (Figure $2 \mathrm{~b}$ ).

The significant abundance of intact myoglobin even at a solution temperature of $92{ }^{\circ} \mathrm{C}$ is surprising. Myoglobin can precipitate at elevated temperature [51, 52], and this may account for the lower signal-to-noise ratio at high temperature. Because the tip of the capillary extends past the resistively heated aluminum collar (see Supplemental Information) and is exposed to laboratory room temperature air, the temperature of the solution in the tip of the capillary is likely lower than that of the solution contained within the region of the heated collar. In addition, rapid evaporative cooling after formation of the electrospray droplet can occur, which could lead to folding and reincorporation of the heme group under these lower-temperature solution
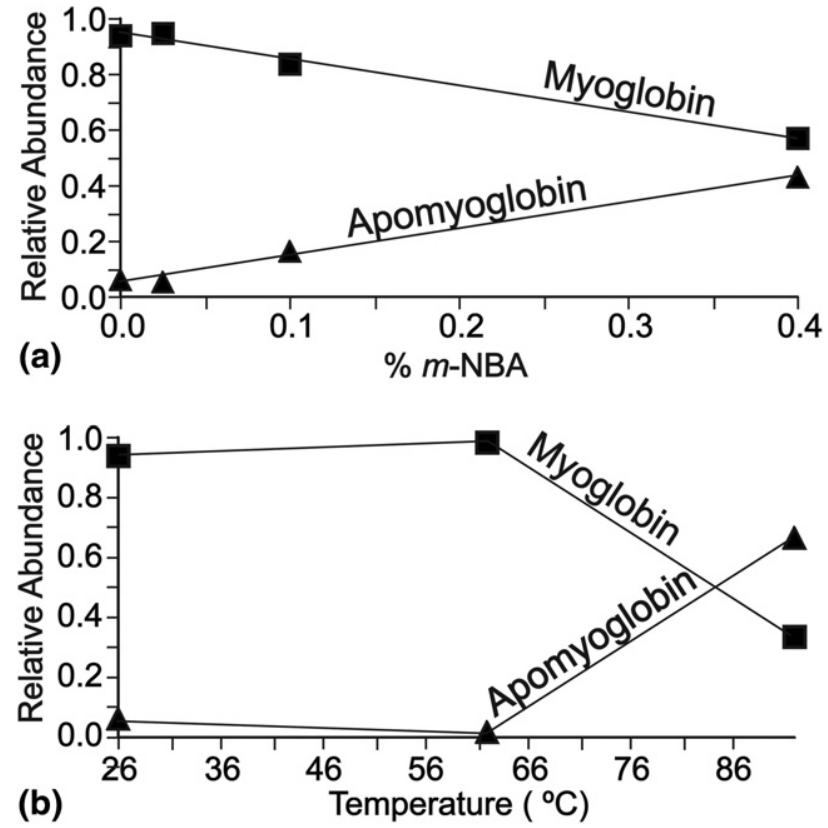

Figure 2. Relative abundances of myoglobin (squares) and apomyoglobin (triangles) as a function of (a) \% $m$-NBA or (b) heating collar temperature. Relative abundances were estimated by summing the intensities of each charge state of a given protein or complex, and dividing that value by the sum of the intensities for all the proteins and complexes.

conditions. A mass spectrum acquired after the heated solution cooled from $92{ }^{\circ} \mathrm{C}$ to $30^{\circ} \mathrm{C}$ shows that the charge state distributions and relative abundances of both myoglobin and apomyoglobin return to the original values measured before heating the solution (data not shown), indicating that the folding/unfolding process is reversible. Results from circular dichroism experiments indicate that myoglobin refolding can take place on the millisecond time frame [53].

\section{NtrC4-RC Complex}

The $\sigma^{54}$ activator protein complex from the thermophilic bacterium Aquifex aeolicus is a homo-oligomer of the protein NtrC4, which is composed of three domains termed R, C, and D [50]. An ESI mass spectrum of a truncation mutant with only the $\mathrm{R}$ and $\mathrm{C}$ domains (NtrC4-RC; $44.9 \mathrm{kDa}$ ) formed from an aqueous solution containing $600 \mathrm{mM}$ ammonium acetate, $\mathrm{pH}=7.8$, is shown in Figure 3a. The predominant signal corresponds to monomer and dimer, but charge state distributions for a trimer, tetramer, and heptamer are also

Table 1. Results for average (and maximum) charge states for myoglobin and apomyoglobin

\begin{tabular}{lcccccrr}
\hline & \multicolumn{4}{c}{ m-NBA (\%) } & & \multicolumn{3}{c}{ Temperature $\left({ }^{\circ} \mathrm{C}\right)$} \\
\cline { 2 - 5 } \cline { 5 - 7 } Myoglobin & 0 & 0.025 & 0.1 & 0.4 & & 26 & 62 \\
\hline \hline Myoglobin & $7.9(9)$ & $8.6(11)$ & $9.8(16)$ & $11.8(16)$ & $7.9(9)$ & $8.2(9)$ & $8.5(10)$ \\
Apomyoglobin & $7.6(9)$ & $8.5(11)$ & $12.2(20)$ & $13.9(20)$ & $7.6(9)$ & $7.5(9)$ & $11.9(17)$ \\
\hline
\end{tabular}




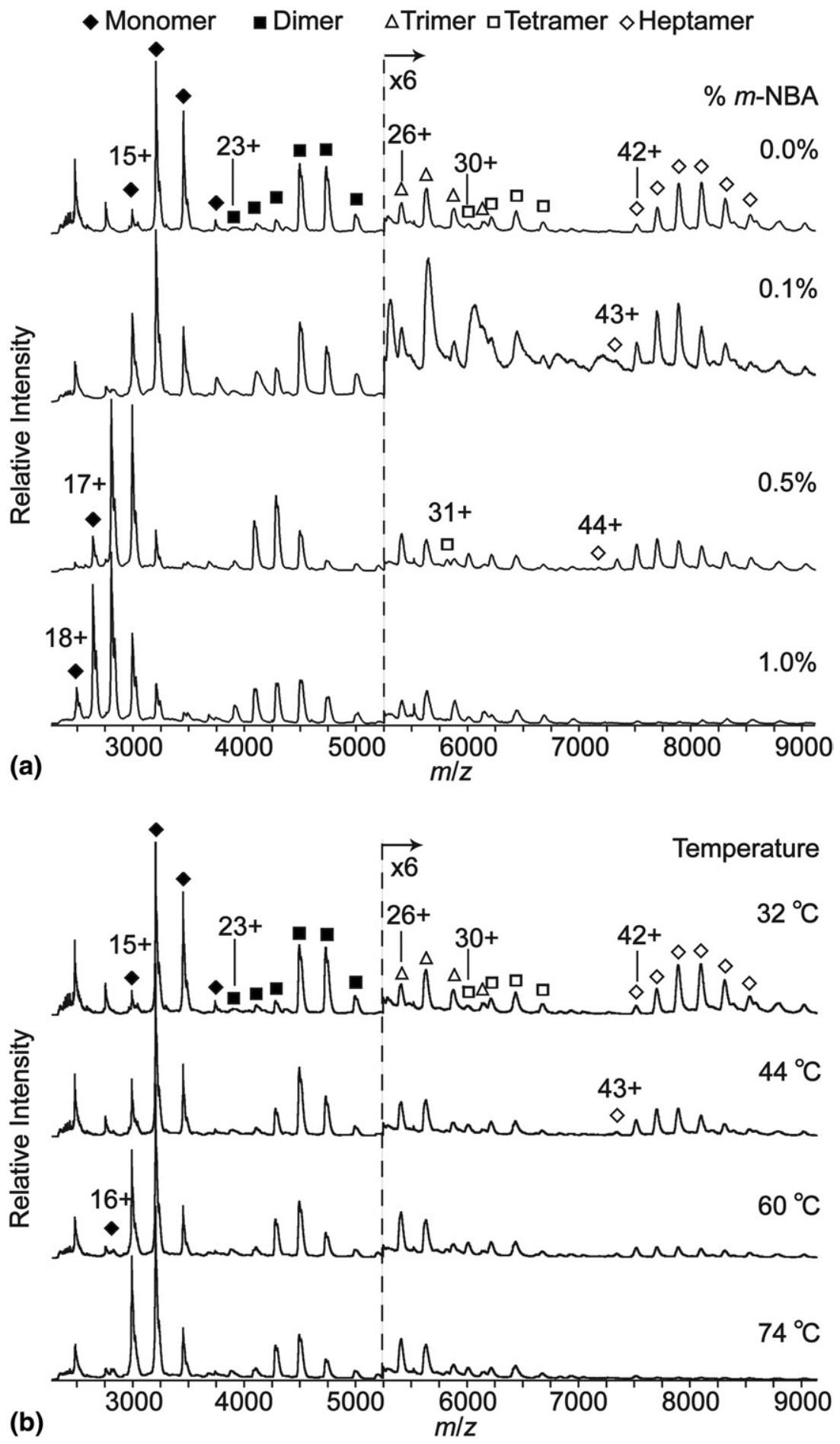

Figure 3. Mass spectra of the NtrC4-RC protein and its homo-oligomers as a function of (a) \% $m$-NBA and (b) heating collar temperature.

observed. ESI spectra of these solutions to which up to 1.0\% $m$-NBA are added are shown in Figure 3a. As was observed for myoglobin, the average (and maximum) charge state of the monomer increases with $m$-NBA concentration; from 13.6 (15) to 16.0 (18) upon the addition of $1.0 \% \mathrm{~m}$-NBA. This charge enhancement effect is also observed for the higher-order complexes
(Table 2) although the relative enhancement is lower. For example, the average (and maximum) charge state for the heptamer without $m$-NBA and with $0.5 \% \mathrm{~m}$ NBA is 35.7 (42) and 40.2 (44), respectively. An increase in the maximum charge state was observed for just the tetramer and heptamer. The relative abundances of these higher-order complexes also changes with in- 
Table 2. Results for average (and maximum) charge states for the NtrC4-RC protein and its homo-oligomers

\begin{tabular}{|c|c|c|c|c|c|c|c|c|}
\hline \multirow[b]{2}{*}{ NtrC4-RC } & \multicolumn{4}{|c|}{$m$-NBA (\%) } & \multicolumn{4}{|c|}{ Temperature $\left({ }^{\circ} \mathrm{C}\right)$} \\
\hline & 0 & 0.10 & 0.50 & 1.0 & 32 & 44 & 60 & 74 \\
\hline Monomer & $13.6(15)$ & $13.9(15)$ & $15.5(17)$ & $16.0(18)$ & $13.6(15)$ & $13.9(15)$ & $14.2(16)$ & $14.2(16)$ \\
\hline Dimer & $19.6(23)$ & $19.8(23)$ & $21.0(23)$ & $20.7(23)$ & $19.6(23)$ & $20.0(23)$ & $20.3(23)$ & $20.3(23)$ \\
\hline Trimer & $24.2(26)$ & $24.2(26)$ & $25.1(26)$ & $24.1(26)$ & $24.2(26)$ & $24.6(26)$ & $24.7(26)$ & $24.7(26)$ \\
\hline Tetramer & $28.3(30)$ & $28.8(30)$ & $29.0(31)$ & $28.1(30)$ & $28.3(30)$ & $28.5(30)$ & $28.7(30)$ & $28.6(30)$ \\
\hline Heptamer & $35.7(42)$ & 40.1 (43) & $40.2(44)$ & $39.1(42)$ & $35.7(42)$ & $38.3(43)$ & $40.2(43)$ & $39.9(42)$ \\
\hline
\end{tabular}

creasing $m$-NBA concentration. The abundance of the heptamer decreases from $\sim 6 \%$ to $<1 \%$ with the addition of $m$-NBA with a concomitant increase in the monomer abundance (Figure $4 \mathrm{a}$ ). These results indicate that not only does $m$-NBA increase the average charge states of proteins and their complexes from aqueous solutions containing high concentrations of ammonium acetate, but the addition of $m$-NBA can also result in a decrease in the abundances of the higherorder complexes.

Results obtained from heating the aqueous solution (600 mM ammonium acetate) containing NtrC4-RC are shown in Figure 3b. Heating has only a minor effect on the charge states of the monomer and dimer (Table 2). For the monomer, the average (and maximum) charge states are $13.6(15)$ and $14.2(16)$ at $32{ }^{\circ} \mathrm{C}$ and $60^{\circ} \mathrm{C}$,

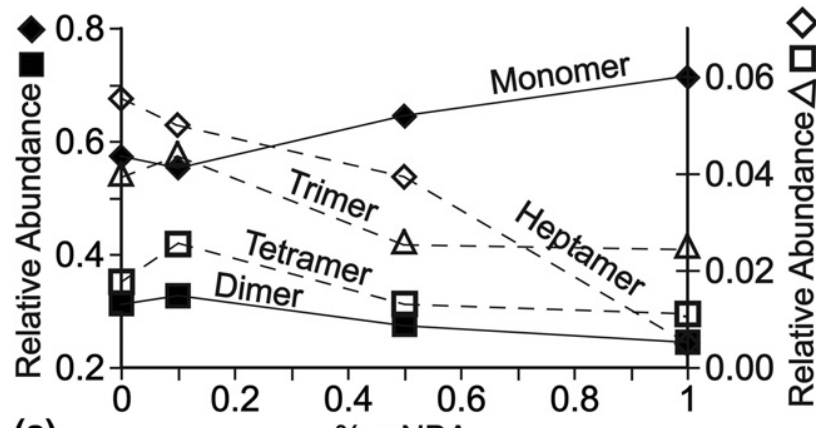

(a) $\% \mathrm{mNBA}$

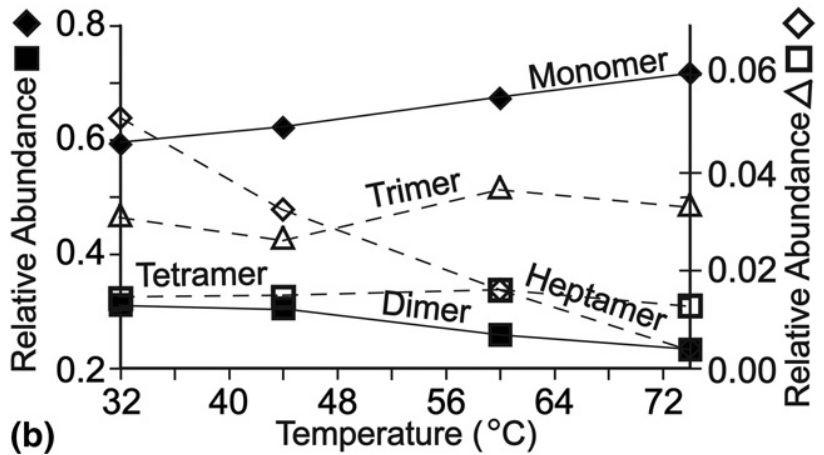

Figure 4. Relative abundances of NtrC4-RC protein and its homo-oligomers as a function of (a) \% $m$-NBA and (b) heating collar temperature. Relative abundances were estimated by summing the intensities of each charge state of a given protein or complex, and dividing that value by the sum of the intensities for all the proteins and complexes. respectively. For the dimer, these corresponding values are 19.6 (23) and 20.3 (23). In contrast, this effect is more apparent for the heptamer, for which the average (and maximum) charge states are 35.7 (42) and 40.2 (43) at $32{ }^{\circ} \mathrm{C}$ and $60^{\circ} \mathrm{C}$, respectively. The slightly lower values at $74{ }^{\circ} \mathrm{C}$ are likely due to poor ion counting statistics owing to the very low abundance of the complex at this temperature.

The relative abundances of the higher-order complexes also change as a function of temperature. The heptamer abundance decreases from $\sim 5 \%$ to $<1 \%$ as the solution temperature is increased from $32{ }^{\circ} \mathrm{C}$ to $74^{\circ} \mathrm{C}$, respectively, with a concomitant increase in both the monomer and dimer abundances over this temperature range.

$P A_{x}\left(L F_{N}\right)_{y}$

Protective antigen (PA) is a $83 \mathrm{kDa}$ protein component of anthrax toxin that binds to host cell surfaces and assembles into a ring-shaped homo-oligomer that can bind lethal factor (LF), a $90.7 \mathrm{kDa}$ protein, after proteolytic activation [49]. The resulting complex forms a transmembrane channel through which LF translocates into the host's cytosol where this enzyme can catalyze a reaction that disrupts the host cell. $\mathrm{LF}_{\mathrm{N}}$ is a $30.9 \mathrm{kDa}$ truncated form of LF that includes the PA binding site. An ESI mass spectrum of these two proteins obtained from an aqueous solution containing 100 $\mathrm{mM}$ ammonium acetate and $5 \mathrm{mM}$ ammonium bicarbonate, $\mathrm{pH}=7.8$, is shown in Figure 5a. The most abundant charge state distribution corresponds to a complex with 7:3 stoichiometry, i.e., $\mathrm{PA}_{7}\left(\mathrm{LF}_{\mathrm{N}}\right)_{3}$. Also apparent at much lower abundance are complexes corresponding to $\mathrm{PA}_{7}\left(\mathrm{LF}_{\mathrm{N}}\right)_{2}$ and $\mathrm{PA}_{8}\left(\mathrm{LF}_{\mathrm{N}}\right)_{4}$. Although much lower in abundance, this recently discovered latter complex may play an important role in the toxicity of anthrax [56]. Some lower order oligomers that are likely intermediates in the formation of both $\mathrm{PA}_{7}\left(\mathrm{LF}_{\mathrm{N}}\right)_{3}$ and $\mathrm{PA}_{8}\left(\mathrm{LF}_{\mathrm{N}}\right)_{4}$ are also observed.

Addition of $m$-NBA results in a slight increase in both the average and maximum charge states of these proteins and protein complexes but this effect is subtle and is only observed at low $m$-NBA concentration. For example, the average (and maximum) charge states increase from 10.5 (12) to 10.8 (12), 43.7 (48) to 44.0 (49), and 47.7 (50) to 48.3 (51) for $\mathrm{LF}_{\mathrm{N}}, \mathrm{PA}_{7}\left(\mathrm{LF}_{\mathrm{N}}\right)_{3}$ and 


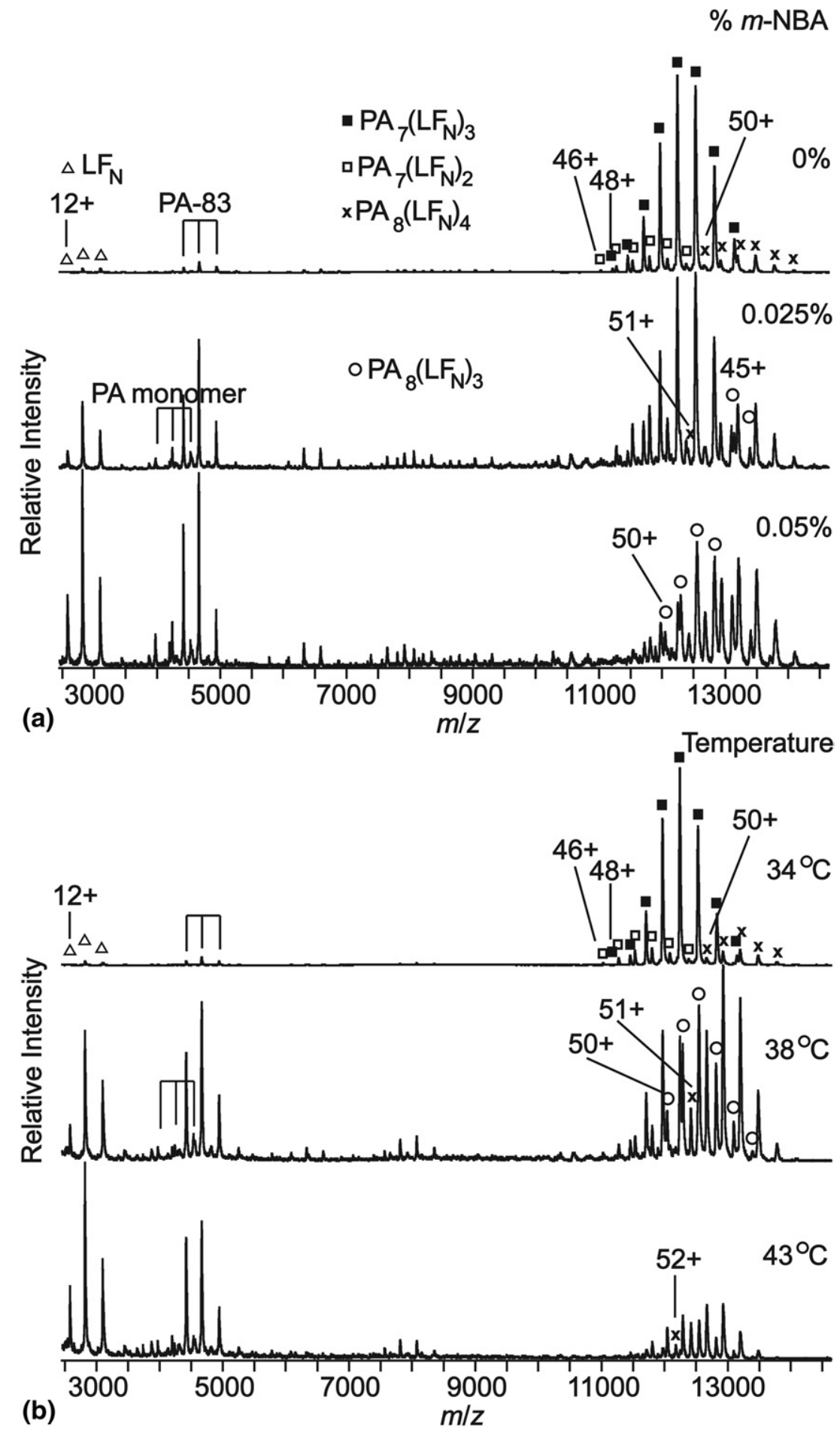

Figure 5. Mass spectra of the proteins and protein complexes from the Anthrax toxin constructs, $\operatorname{PAx}\left(\mathrm{LF}_{\mathrm{N}}\right) \mathrm{y}$, as a function of (a) \% $m$-NBA and (b) heating collar temperature. PA monomer is the $63 \mathrm{kDa}$ product of proteolytic activation of PA-83, which forms the heptameric and octameric rings to which $\mathrm{LF}_{\mathrm{N}}$ binds. The absolute abundance of PA- 83 does not change significantly in any of the experimental conditions, indicating the heptameric and octameric complexes dissociate in solution by loss of $\mathrm{LF}_{\mathrm{N}}$ (see text). The charge state distributions with low abundance between $\mathrm{m} / \mathrm{z} 5,00$ and 11,000 are substoichiometric complexes of PA and $\mathrm{LF}_{\mathrm{N}}$ that do not change significantly in any of the experimental conditions.

$\mathrm{PA}_{8}\left(\mathrm{LF}_{\mathrm{N}}\right)_{4}$, respectively, upon the addition of $0.01 \%$ $m$-NBA (Table 3). Higher concentrations of $m$-NBA result in only a minor increase in these values for $L_{N}$ but not for these two complexes.
Upon the addition of even small amounts of $m$-NBA to the solution containing $\mathrm{PA}$ and $\mathrm{LF}_{\mathrm{N}}$, the relative abundance of the $\mathrm{PA}_{7}\left(\mathrm{LF}_{\mathrm{N}}\right)_{3}$ complex decreases substantially, whereas the relative abundances of both the 
Table 3. Results for average (and maximum) charge states for $\operatorname{LF}_{N}$ monomer and $\operatorname{PA}_{x}\left(\operatorname{LF}_{N}\right)_{y}$ protein complexes

\begin{tabular}{|c|c|c|c|c|c|c|c|c|c|}
\hline \multirow[b]{2}{*}{$\mathrm{PA}_{x}\left(L F_{N}\right)_{y}$} & \multicolumn{5}{|c|}{$m$-NBA (\%) } & \multicolumn{4}{|c|}{ Temperature $\left({ }^{\circ} \mathrm{C}\right)$} \\
\hline & 0 & 0.01 & 0.025 & 0.038 & 0.050 & 26 & 34 & 38 & 43 \\
\hline $\mathrm{LF}_{\mathrm{N}}$ & $10.5(12)$ & $10.8(12)$ & $10.8(12)$ & $10.9(12)$ & $11.0(12)$ & $10.5(12)$ & $10.7(12)$ & $10.8(12)$ & $10.9(12)$ \\
\hline $\mathrm{PA}_{7}\left(\mathrm{LF}_{\mathrm{N}}\right)_{2}$ & $43.0(46)$ & $43.2(46)$ & $42.9(45)$ & $43.0(46)$ & $43.3(44)$ & $43.0(46)$ & $43.3(46)$ & $43.9(46)$ & N/A \\
\hline $\mathrm{PA}_{7}\left(\mathrm{LF}_{\mathrm{N}}\right)_{3}$ & $43.7(48)$ & 44.0 (49) & $43.5(47)$ & $43.6(47)$ & $43.3(46)$ & $43.7(48)$ & $44.0(48)$ & 43.9 (47) & $45.5(46)$ \\
\hline $\mathrm{PA}_{8}\left(\mathrm{LF}_{\mathrm{N}}\right)_{3}$ & N/A & N/A & $44.7(45)$ & $44.8(45)$ & $47.4(50)$ & N/A & N/A & $48.6(50)$ & $48.7(50)$ \\
\hline $\mathrm{PA}_{8}\left(\mathrm{LF}_{\mathrm{N}}\right)_{4}$ & $47.7(50)$ & $48.3(51)$ & $47.7(51)$ & $48.3(51)$ & $48.2(51)$ & $47.7(50)$ & $48.2(50)$ & $48.8(51)$ & $49.7(52)$ \\
\hline
\end{tabular}

$\mathrm{PA}_{7}\left(\mathrm{LF}_{\mathrm{N}}\right)_{2}$ and $\mathrm{PA}_{8}\left(\mathrm{LF}_{\mathrm{N}}\right)_{4}$ increase (Figure 5a and Figure 6a). A concurrent increase in the abundance of $\mathrm{LF}_{\mathrm{N}}$ indicates that $\mathrm{PA}_{7}\left(\mathrm{LF}_{\mathrm{N}}\right)_{3}$ dissociates by loss of $\mathrm{LF}_{\mathrm{N}}$ to form $\mathrm{PA}_{7}\left(\mathrm{LF}_{\mathrm{N}}\right)_{2}$ or more directly to the individual monomer constituents. PA monomer was observed at low relative abundance for both higher $m$-NBA concentrations and temperature.

Results from heating the solution containing PA and $\mathrm{LF}_{\mathrm{N}}$, are shown in Figure $5 \mathrm{~b}$. Increasing the solution temperature from $26^{\circ} \mathrm{C}$ to $43^{\circ} \mathrm{C}$ results in a change in the average (and maximum) charge state from 10.5 (12) to 10.9 (12), 43.7 (48) to 45.5 (46), and 47.7 (50) to 49.7 (52) for $\mathrm{LF}_{\mathrm{N}}, \mathrm{PA}_{7}\left(\mathrm{LF}_{\mathrm{N}}\right)_{3}$ and $\mathrm{PA}_{8}\left(\mathrm{LF}_{\mathrm{N}}\right)_{4}$, respectively. As observed with the addition of $m$-NBA, the relative abundance of $\mathrm{PA}_{7}\left(\mathrm{LF}_{\mathrm{N}}\right)_{3}$ decreases whereas that for $\mathrm{PA}_{8}\left(\mathrm{LF}_{\mathrm{N}}\right)_{4}$ increases with increasing tempera-
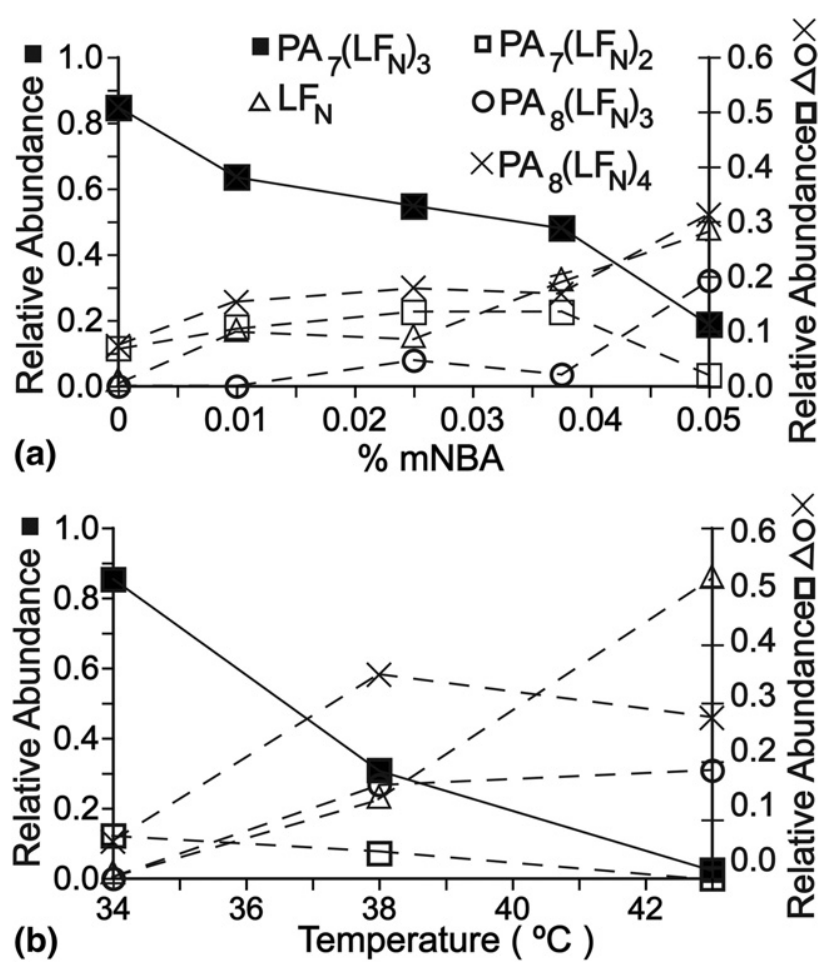

Figure 6. Relative abundances for the proteins and protein complexes from the anthrax toxin constructs, $\operatorname{PAx}\left(\mathrm{LF}_{\mathrm{N}}\right) \mathrm{y}$, as a function of (a) \% $m$-NBA and (b) heating collar temperature. Relative abundances were estimated by summing the intensities of each charge state of a given protein or complex, and dividing that value by the sum of the intensities for all the proteins and complexes. ture (Figure $5 b$ and Figure $6 b$ ). The increase in the relative abundances of the $\mathrm{LF}_{\mathrm{N}}$ monomer is consistent with dissociation of the larger complexes as was the case for addition of $m$-NBA. The abundance of $\mathrm{PA}_{7}\left(\mathrm{LF}_{\mathrm{N}}\right)_{2}$ relative to $\mathrm{PA}_{7}\left(\mathrm{LF}_{\mathrm{N}}\right)_{3}$ increases from $8 \%$ to $12 \%$ when the solution is heated from $34{ }^{\circ} \mathrm{C}$ to $38^{\circ} \mathrm{C}$, which is consistent with the former complex being formed by the loss of a single $\mathrm{LF}_{\mathrm{N}}$ from $\mathrm{PA}_{7}\left(\mathrm{LF}_{\mathrm{N}}\right)_{3}$ as opposed to higher thermal stability of the smaller complex. The absolute intensity of $\mathrm{PA}_{8}\left(\mathrm{LF}_{\mathrm{N}}\right)_{4}$ decreases only slightly upon heating to $38^{\circ} \mathrm{C}$ indicating that the heptameric complex does not interconvert to the octameric complex and that the octameric complex is more thermally stable than the heptameric complex. However, $\mathrm{PA}_{8}\left(\mathrm{LF}_{\mathrm{N}}\right)_{3}$ is observed at $38^{\circ} \mathrm{C}$, and the abundance of this complex is roughly equal to that of $\mathrm{PA}_{8}\left(\mathrm{LF}_{\mathrm{N}}\right)_{4}$ at $43^{\circ} \mathrm{C}$, so the enhanced thermal stability of the octameric complex compared with the heptameric complex appears modest. The lower signal-to-noise ratio at both the higher temperature and higher $m$-NBA concentration is likely due to the low solubility of PA oligomers that are not bound to at least two $\mathrm{LF}_{\mathrm{N}}$ proteins, although other factors may also play a role.

To determine if the increased charging observed by adding $m$-NBA was due to factors associated with the electrospray ionization process rather than a result of a solution-phase reaction that occurs before electrospray, a solution containing $0.05 \% m-\mathrm{NBA}$ was prepared and allowed to sit at room temperature for $30 \mathrm{~min}$. The solution was centrifuged and dialyzed (1:10,000; $10 \mathrm{kDa}$ cutoff) against $200 \mathrm{mM}$ ammonium acetate, $\mathrm{pH}=7.8$. Because PA oligomers not bound to $\mathrm{LF}_{\mathrm{N}}$ have limited solubility in ammonium acetate solutions, dissociation of these complexes by reaction or interaction with $m$-NBA would result in a significant loss of signal as the precipitate would be removed by centrifugation. A mass spectrum obtained from the dialyzed supernatant was identical to that obtained without adding $m$-NBA (data not shown), indicating that low concentrations of $m$-NBA do not change the relative abundances of the higher-order complexes.

\section{Discussion}

Because the boiling point of $m$-NBA $\left(177^{\circ} \mathrm{C}\right.$ at 3 Torr $)$ [43] is much higher than that of water $\left(100{ }^{\circ} \mathrm{C}\right.$ at 760 Torr) [43], preferential evaporation of water from droplets containing even small amounts of $m$-NBA will 
occur. This will result in droplets that are enriched in $m$-NBA with increasing droplet lifetime. Since the surface tension of $m$-NBA is lower than that of water, the charge density on a droplet at the Rayleigh limit is lower. Thus, in the absence of any conformational effects, analyte charging via a charge residue mechanism should be lower for aqueous droplets that contain $m$-NBA. However, because of the lower vapor pressure of $m$-NBA, the rate of evaporative cooling of the droplet will be lower so that droplets containing $m$-NBA will have a higher temperature and longer lifetime than those that just contain water. Since the temperature of the droplets containing $m-\mathrm{NBA}$ is higher, conformational changes of the analytes contained in the droplets can occur. Typically, heating aqueous solutions containing protein and noncovalent protein complexes can result in significant denaturation and/or dissociation.

The similarity between spectra of these complexes electrosprayed from solutions containing $m$-NBA and those that are heated is striking, both with respect to the increase in the average and maximum charge state and with respect to the pathway and extent of dissociation observed. Furthermore, no evidence of gas-phase dissociation, i.e., asymmetric charge partitioning [54, 55], of any of the complexes was observed, indicating that dissociation occurred in solution. These results indicate that the increased charging of complexes observed by adding $m$-NBA to aqueous solutions are due to structural changes of the complex caused by solution heating in the ESI droplet. This suggests that the surface area of the entire complex is increasing either due to partial denaturation of one or more individual constituents or due to more gross conformational changes.

The similarity between spectra with $m$-NBA and from heated solutions is more pronounced for the larger complexes. In the case of myoglobin, the extent of charging and loss of heme is greater with increasing $m$-NBA concentration than from heated solutions. Even at $92{ }^{\circ} \mathrm{C}$, the abundance of myoglobin is significant. A complicating factor in these experiments is that the solution in the capillary tip, which is surrounded by ambient air at room temperature, may be lower than that surrounded by the heating collar. In addition, droplets formed by electrospray will undergo evaporative cooling in competition with collisional heating. Thus, the temperature in the droplet is unknown, but it is likely to be significantly below the original heated solution temperature. Thus, a small protein such as myoglobin, which can fold rapidly [53], may do so in the taper of the electrospray emitter or electrospray droplet before formation of the isolated gas-phase ion. In contrast, a droplet containing $m$-NBA will have a higher temperature due to slower evaporative cooling but comparable collisional heating. The higher droplet temperature likely results in significant unfolding and loss of the heme group, resulting in the higher observed charging with increasing amounts of $m$-NBA.

With either $m$-NBA or with solution heating, myoglobin apparently reaches a maximum extent of charg- ing before loss of the heme occurs. The average charge state of myoglobin is $84 \%$ that of apomyoglobin with $0.4 \% \mathrm{~m}$-NBA and is $71 \%$ at $92{ }^{\circ} \mathrm{C}$. This observation is consistent with the thermal unfolding mechanism described by Awad and Deranleau [52], who proposed that a conformation change in the region of the heme group occurs first, followed by unfolding of the helical regions, and then precipitation.

A similar result is obtained for the NtrC4-RC monomer and to a lesser extent the homodimer. Both show significantly increased charging upon the addition of increasing amounts of $m$-NBA but this effect is less upon heating the solutions. In contrast, charge state distributions for the heptameric complex are remarkably similar upon heating or upon addition of $m$-NBA. This result can be rationalized by the relative time frame for assembly of a large macromolecular complex, which typically requires significantly more time than folding of an individual protein that can occur rapidly and on the time frame of the droplet lifetime. Once the complex is dissociated at high temperature, there is insufficient time upon cooling of the electrospray droplet to reform the higher-order structures, whereas folding of the individual constituent proteins is rapid.

Results for the PA/ $\mathrm{LF}_{\mathrm{N}}$ complexes also indicate that $m$-NBA results in heating of the electrospray droplets and that the increased charging observed for the higherorder complexes is a result of structural changes caused by this heating. The higher droplet temperature with $m$-NBA added is also strongly indicated by the striking similarity between the relative abundances of the $\mathrm{PA}_{7}\left(\mathrm{LF}_{\mathrm{N}}\right)_{3}$ to $\mathrm{PA}_{8}\left(\mathrm{LF}_{\mathrm{N}}\right)_{4}$ with increasing $m$-NBA or with increasing temperature. These solution-phase heating experiments show that $\mathrm{PA}_{8}\left(\mathrm{LF}_{\mathrm{N}}\right)_{4}$ is more thermally stable than $\mathrm{PA}_{7}\left(\mathrm{LF}_{\mathrm{N}}\right)_{3}$ and becomes the dominant form of the higher order complex at high temperature as is also the case upon addition of $0.05 \% m$-NBA.

\section{Conclusions}

Addition of $m$-NBA can result in an increase in both the average and maximum charge state of proteins and noncovalent complexes formed by ESI from aqueous solutions despite the lowering of the surface tension of droplets from which these ions are formed. Similar results are obtained from heated solutions containing the same complexes but to which no $m$-NBA is added. Electrospray droplets that contain $m$-NBA will undergo preferential evaporation of water resulting in increasing concentrations of $m$-NBA. Because $m$-NBA has a low vapor pressure, the rate of evaporative cooling of droplets that are enriched in $m$-NBA will be lower resulting in a higher droplet temperature. Structural changes to complexes that occur as a result of the higher droplet temperature appear to be the primary origin of the increased charging observed with $m$-NBA in aqueous solution, although other factors may also play a role.

The enhanced charging observed by adding $m$-NBA to aqueous solutions containing individual proteins is 
even more pronounced than that observed upon solution heating. Although proteins can unfold in heated solutions, they can also rapidly fold during the lifetime of an electrospray droplet, which is evaporatively cooled to lower temperatures. In contrast, assembly of macromolecular complexes typically occurs more slowly, so that the effects of heating a solution and adding $m$-NBA to room temperature solutions on the resulting charge state distributions and the extents of dissociation are remarkably similar for the larger complexes.

By comparison, experiments in which effects of analyte conformation are carefully controlled indicate that addition of $m$-NBA to aqueous solutions result in a decrease of the charge states due to a lowering of the surface tension of the electrospray droplet, but an increase in charging is observed when organic solutions of lower initial surface tension are used [19]. The results here show that conformations of macromolecular complexes can be affected by the increased droplet temperature when $m$-NBA is added to aqueous electrospray solutions and that significant structural changes and even dissociation of the complexes can occur. This mechanism for charge enhancement from aqueous solutions containing $m$-NBA can explain the observation of Loo and coworkers who found that $m$-NBA can increase the charge state of protein complexes, although other factors may also play a role. This illustrates that surface tension is just one of many competing factors that can influence analyte charging by ESI. These results also indicate that additives such as $m$-NBA, which can enhance charging of macromolecular complexes, should be used with caution because structural changes and even dissociation of the complex as a result of droplet heating may occur.

\section{Acknowledgments}

The authors thank Geoffrey K. Feld, Bryan A. Krantz, Joseph D. Batchelor, and David E. Wemmer for protein complex samples and thank the National Institutes of Health (R01GM064712-08) for generous financial support.

\section{Appendix A Supplementary Material}

Supplementary material associated with this article may be found in the online version at doi:10.1016/ j.jasms.2009.06.012.

\section{References}

1. Wong, S. F.; Meng, C. K.; Fenn, J. B. Multiple Charging in Electrospray Ionization of Poly(Ethylene Glycols). I. Phys. Chem 1988, 92, 546-550.

2. McEwen, C. N.; Simonsick, W. J.; Larsen, B. S.; Ute, K.; Hatada, K. The Fundamentals of Applying Electrospray-Ionization Mass-Spectrometry to Low-Mass Poly(Methyl Methacrylate) Polymers. J. Am. Soc. Mass Spectrom. 1995, 6, 906-911.

3. Fenn, J. B.; Mann, M.; Meng, C. K.; Wong, S. F.; Whitehouse, C. M. Electrospray Ionization for Mass-Spectrometry of Large Biomolecules. Science 1989, 246, 64-71

4. Wunschel, D. S.; Tolic, L. P.; Feng, B. B.; Smith, R. D. Electrospray Ionization Fourier Transform Ion Cyclotron Resonance Analysis of
Large Polymerase Chain Reaction Products. J. Am. Soc. Mass Spectrom. 2000, 11, 333-337.

5. Loo, J. A. Studying Noncovalent Protein Complexes by Electrospray Ionization Mass Spectrometry. Mass Spectrom. Rev. 1997, 16, 1-23.

6. Rostom, A. A.; Fucini, P.; Benjamin, D. R.; Juenemann, R.; Nierhaus, K. H.; Hartl, F. U.; Dobson, C. M.; Robinson, C. V. Detection and Selective Dissociation of Intact Ribosomes in a Mass Spectrometer. Proc. Natl. Acad. Sci. U.S.A. 2000, 97, 5185-5190.

7. Heck, A. J. R.; van den Heuvel, R. H. H. Investigation of Intact Protein Complexes by Mass Spectrometry. Mass Spectrom. Rev. 2004, 23, 368 389.

8. Benesch, J. L. P. Collisional Activation of Protein Complexes: Picking Up the Pieces. J. Am. Soc. Mass Spectrom. 2009, 20, 341-348.

9. Siuzdak, G.; Bothner, B.; Yeager, M.; Brugidou, C.; Fauquet, C. M.; Hoey, K.; Chang, C. M. Mass Spectrometry and Viral Analysis. Chem. Biol. 1996, 3, 45-48.

10. Fuerstenau, S. D.; Benner, W. H.; Thomas, J. J.; Brugidou, C.; Bothner, B. Siuzdak, G. Mass Spectrometry of an Intact Virus. Angew. Chem. Int. Ed. 2001, 40, 542-544

11. Perry, R. H.; Cooks, R. G.; Noll, R. J. Orbitrap Mass Spectrometry: Instrumentation, Ion Motion, and Applications. Mass Spectrom. Rev. 2008, 27, 661-699.

12. Marshall, A. G.; Hendrickson, C. L.; Jackson, G. S. Fourier Transform Ion Cyclotron Resonance Mass Spectrometry: A Primer. Mass Spectrom. Rev. 1998, 17, 1-35.

13. Schaub, T. M.; Hendrickson, C. L.; Horning, S.; Quinn, J. P.; Senko, M. W.; Marshall, A. G. High-Performance Mass Spectrometry: Fourier Transform Ion Cyclotron Resonance at 14.5 Tesla. Anal. Chem. 2008, 80, 3985-3990.

14. Han, X. M.; Jin, M.; Breuker, K.; McLafferty, F. W. Extending Top-Down Mass Spectrometry to Proteins with Masses Greater Than 200 Kilodaltons. Science 2006, 314, 109-112.

15. Fenn, J. B. Ion Formation from Charged Droplets-Roles of Geometry, Energy, and Time. J. Am. Soc. Mass Spectrom. 1993, 4, 524-535.

16. Kebarle, P. A Brief Overview of the Present Status of the Mechanisms Involved in Electrospray Mass Spectrometry. J. Mass Spectrom. 2000, 35, $804-817$.

17. Cech, N. B.; Enke, C. G. Practical Implications of Some Recent Studies in Electrospray Ionization Fundamentals. Mass Spectrom. Rev. 2001, 20, 362-387.

18. Cech, N. B.; Enke, C. G. Effect of Affinity for Droplet Surfaces on the Fraction of Analyte Molecules Charged During Electrospray Droplet Fission. Anal. Chem. 2001, 73, 4632-4639.

19. Iavarone, A. T.; Williams, E. R. Mechanism of Charging and Supercharging Molecules in Electrospray Ionization. J. Am. Chem. Soc. 2003, $125,2319-2327$

20. Grandori, R. Origin of the Conformation Dependence of Protein Charge-State Distributions in Electrospray Ionization Mass Spectrometry. J. Mass Spectrom. 2003, 38, 11-15.

21. Hogan, C. J.; Carroll, J. A.; Rohrs, H. W.; Biswas, P.; Gross, M. L. Charge Carrier Field Emission Determines the Number of Charges on Native State Proteins in Electrospray Ionization. J. Am. Chem. Soc. 2008, 130, 6926-6927.

22. Chowdhury, S. K.; Katta, V.; Chait, B. T. Probing ConformationalChanges in Proteins by Mass-Spectrometry. J. Am. Chem. Soc. 1990, 112, 9012-9013.

23. Konermann, L.; Douglas, D. J. Equilibrium Unfolding of Proteins Monitored by Electrospray Ionization Mass Spectrometry: Distinguishing Two-State from Multi-State Transitions. Rapid Commun. Mass Spectrom. 1998, 12, 435-442.

24. Iavarone, A. T.; Jurchen, J. C.; Williams, E. R. Effects of Solvent on the Maximum Charge State and Charge State Distribution of Protein Ions Produced by Electrospray Ionization. J. Am. Soc. Mass Spectrom. 2000, 11, 976-985.

25. Loo, R. R. O.; Smith, R. D. Proton-Transfer Reactions of MultiplyCharged Peptide and Protein Cations and Anions. J. Mass Spectrom. 1995, 30, 339-347.

26. Williams, E. R. Proton Transfer Reactivity of Large Multiply Charged Ions. J. Mass Spectrom. 1996, 31, 831-842.

27. Benkestock, K.; Sundqvist, G.; Edlund, P. O.; Roeraade, J. Influence of Droplet Size, Capillary-Cone Distance and Selected Instrumental Parameters for the Analysis of Noncovalent Protein-Ligand Complexes by Nano-Electrospray Ionization Mass Spectrometry. J. Mass Spectrom. 2004, 39, 1059-1067.

28. Page, J. S.; Kelly, R. T.; Tang, K.; Smith, R. D. Ionization and Transmission Efficiency in an Electrospray Ionization-Mass Spectrometry Interface. J. Am. Soc. Mass Spectrom. 2007, 18, 1582-1590.

29. Scalf, M.; Westphall, M. S.; Smith, L. M. Charge Reduction Electrospray Mass Spectrometry. Anal. Chem. 2000, 72, 52-60.

30. Stephenson, J. L.; McLuckey, S. A. Charge Manipulation for Improved Mass Determination of High-Mass Species and Mixture Components by Electrospray Mass Spectrometry. J. Mass Spectrom. 1998, 33, 664-672.

31. Dobo, A.; Kaltashov, I. A. Detection of Multiple Protein Conformational Ensembles in Solution Via Deconvolution of Charge-State Distributions in ESI MS. Anal. Chem. 2001, 73, 4763-4773.

32. Iavarone, A. T.; Jurchen, J. C.; Williams, E. R. Supercharged Protein and Peptide Ions Formed by Electrospray Ionization. Anal. Chem. 2001, 73, $1455-1460$.

33. Iavarone, A. T.; Williams, E. R. Supercharging in Electrospray Ionization: Effects on Signal and Charge. Int. J. Mass Spectrom. 2002, 219, 63-72. 
34. Iavarone, A. T.; Williams, E. R. Collisionally Activated Dissociation of Supercharged Proteins Formed by Electrospray Ionization. Anal. Chem. 2003, 75, 4525-4533.

35. Davies, N. W.; Wiese, M. D.; Browne, S. G. A. Characterization of Major Peptides in 'Jack Jumper' Ant Venom by Mass Spectrometry. Toxicon 2004, 43, 173-183.

36. Madsen, J. A.; Brodbelt, J. S. Comparison of Infrared Multiphoton Dissociation and Collision-Induced Dissociation of Supercharged Peptides in Ion Traps. J. Am. Soc. Mass Spectrom. 2009, 20, 349-358.

37. Sze, S. K.; Ge, Y.; Oh, H.; McLafferty, F. W. Top-Down Mass Spectrometry of a 29-kDa Protein for Characterization of Any Posttranslational Modification to within One Residue. Proc. Natl. Acad. Sci. U.S.A. 2002, 99, 1774-1779.

38. Kjeldsen, F.; Giessing, A. M. B.; Ingrell, C. R.; Jensen, O. N. Peptide Sequencing and Characterization of Post-Translational Modifications by Enhanced Ion-Charging and Liquid Chromatography Electron-Transfer Dissociation Tandem Mass Spectrometry. Anal. Chem. 2007, 79, 92439252.

39. Zubarev, R. A.; Horn, D. M.; Fridriksson, E. K.; Kelleher, N. L.; Kruger, N. A.; Lewis, M. A.; Carpenter, B. K.; McLafferty, F. W. Electron Capture Dissociation for Structural Characterization of Multiply Charged Protein Cations. Anal. Chem. 2000, 72, 563-573.

40. Iavarone, A. T.; Paech, K.; Williams, E. R. Effects of Charge State and Cationizing Agent on the Electron Capture Dissociation of a Peptide. Anal. Chem. 2004, 76, 2231-2238.

41. Stephenson, J. L.; McLuckey, S. A. Ion/Ion Reactions in the Gas Phase: Proton Transfer Reactions Involving Multiply-Charged Proteins. J. Am. Chem. Soc. 1996, 118, 7390-7397.

42. Lord Rayleigh. Philos. Mag. 1882, 14, 184-186.

43. CRC Handbook of Chemistry and Physics. In [Online] 89th ed.; D. R. Lide, Ed. 2008-2009.

44. Scherrenberg, R.; Coussens, B.; van Vliet, P.; Edouard, G.; Brackman, J.; de Brabander, E.; Mortensen, K. The Molecular Characteristics of Poly(Propyleneimine) Dendrimers as Studied with Small-Angle Neutron Scattering, Viscosimetry, and Molecular Dynamics. Macromolecules 1998, 31, 456-461.

45. Samalikova, M.; Grandori, R. Protein Charge-State Distributions in Electrospray-Ionization Mass Spectrometry Do Not Appear to Be Lim- ited by the Surface Tension of the Solvent. J. Am. Chem. Soc. 2003, 125, 13352-13353.

46. Samalikova, M.; Matecko, I.; Muller, N.; Grandori, R. Interpreting Conformational Effects in Protein Nano-ESI-MS Spectra. Anal. Bioanal. Chem. 2004, 378, 1112-1123.

47. Samalikova, M.; Grandori, R. Testing the Role of Solvent Surface Tension in Protein Ionization by Electrospray. J. Mass Spectrom. 2005, 40, 503-510.

48. Lomeli, S. H.; Yin, S.; Ogorzalek Loo, R. R.; Loo, J. A. Increasing Charge While Preserving Noncovalent Protein Complexes for ESI-MS. J. Am. Soc. Mass Spectrom. 2009, 20, 593-596.

49. Krantz, B. A.; Finkelstein, A.; Collier, R. J. Protein Translocation Through the Anthrax Toxin Transmembrane Pore Is Driven by a Proton Gradient. J. Mol. Biol. 2006, 355, 968-979.

50. Batchelor, J. D.; Doucleff, M.; Lee, C. J.; Matsubara, K.; De Carlo, S. Heideker, J.; Lamers, M. H.; Pelton, J. G.; Wemmer, D. E. Structure and Regulatory Mechanism of Aquifex Aeolicus NtrC4: Variability and Evolution in Bacterial Transcriptional Regulation. J. Mol. Biol. 2008, 384 1058-1075.

51. Acampora, G.; Hermans, J. Reversible Denaturation of Sperm Whale Myoglobin. I. Dependence on Temperature, $\mathrm{pH}$, and Composition. J. Am. Chem. Soc. 1967, 89, 1543-1547.

52. Awad, E. S. Deranleau, D. A. Thermal Denaturation of Myoglobin .I. Kinetic Resolution of Reaction Mechanism. Biochemistry 1968, 7, 17911795.

53. Pflumm, M.; Luchins, J.; Beychok, S. Stopped-Flow Circular-Dichroism Methods Enzymol. 1986, 130, 519-534.

54. Jurchen, J. C.; Williams, E. R. Origin of Asymmetric Charge Partitioning in the Dissociation of Gas-Phase Protein Homodimers. J. Am. Chem. Soc. 2003, 125, 2817-2826.

55. Jurchen, J. C.; Garcia, D. E.; Williams, E. R. Further Studies on the Origins of Asymmetric Charge Partitioning in Protein Homodimers. J. Am. Soc. Mass Spectrom. 2004, 15, 1408-1415.

56. Kintzer, A. F.; Thoren, K. L.; Sterling, H. J.; Dong, K. C.; Feld, G. K. Tang, I. I.; Zhang, T. I.; Williams, E. R.; Berger, J. M.; Krantz, B. A. The Protective Antigen Component of Anthrax Toxin Forms Functional Octameric Complexes. J. Mol. Biol. 2009, doi: 10.1016/j.jmb.2009.07.037. 